\title{
Visualising the Ephemeral
}

\author{
Jayne Wilton
}

\section{Part i: A History in Epitomes}

Our experience of breath is individual and multisensory. I shall explore what visual art can contribute, consciously or unconsciously, to our encounter with the breath. In Feeling Beauty: the Neuroscience of Aesthetic Experience Gabrielle Starr suggests that vision is an 'exploratory activity', and that though 'aesthetic pleasures may sometimes seem to grab us ... often we must work to meet them half way'. ${ }^{1}$ A unique, proprioceptive experience can be evoked through connecting our outer world reality to the inner world of our imagination. The artwork provides a framework through which we can create empathy and construct our personal gestalt. From my experience as a practising artist I have drawn together examples from the vast range of visual art that has engaged literally, poetically, politically, and spiritually with the breath. Through these works I hope to illustrate the potential of visual art to offer insights into this elusive animating force.

It seems pertinent that the very earliest visual art, Palaeolithic paintings in the Cueva de las Manos (Cave of Hands), Santa Cruz, Argentina, is thought to be created by the spent breath. ${ }^{2}$ The out-breath was harnessed

J. Wilton $(\varangle)$

Berkhamsted, UK

(C) The Author(s) 2021 485

D. Fuller et al. (eds.), The Life of Breath in Literature, Culture and Medicine, Palgrave Studies in Literature, Science and Medicine, https://doi.org/10.1007/978-3-030-74443-4_23 
to blow pigment against the resistance of a hand, enabling us to reach out and trace the breath of our ancestors. Throughout history artists have continued to grapple with creating vessels to capture the breath and make the ephemeral process of breathing visible. The bubble was the translucent vessel which provided material for earnest exploration in Jean-Baptiste Chardin's Soap Bubbles (1734) in which he aims to communicate absorption, reflection, and reverie. John Everett Millais' Bubbles (1886) is a more sentimental capture of the breath-of which Christiana Payne, writing on air, observes, 'the blowing of bubbles was well established in art as a metaphor for the vanity of human aspirations, along with flying kites and building card tables'. ${ }^{3}$ Both these works encapsulate an element of wonder at the ability of this transparent substrate to capture both breath and our imagination.

From the bubble evolved the more resilient balloon. Piero Manzoni's Fiato d'artista (Artist's Breath, 1960) started life as an ebullient and robust red balloon tethered to a wooden block. Today this work exists as a red mass of crumpled rubber, the once cheery balloon deflated and defeated. The internal cavity which held the artist's forceful if short-lived breath has become a humble monument to the inevitable transience of human existence. Manzoni's work anticipates the genre of arte povera in which breath as muse and art material allowed Giuseppe Penone to create iconic sculptures and drawings including Breath 5 and Breath of Clay (1978) - enigmatic works to catalyse contemplation of our own experience of the breath. The poetry of Penone's work contrasts with the harsher nature of his contemporary Wincenty Dunikowski-Duniko's Breath works (1976), where the literal gesture of breathing out onto glass was captured photographically and called 'Moment Art'.

The ability of visual art to be static or dynamic comes into consideration in Pulmonary Space (2009) by Philippe Rahm. This is a tragi-comic sculpture-installation-performance where instruments of an ensemble play into a fabric bag which responds to the interaction creating a contemporary and fluid exploration of gaseous exchange. I find the words with which Rahm describes the breath as affecting as the work itself: 'tangible mutation of air according to a specific wave length ... a pressure point placed upon the air in a defined space ... a bodily temperature of close to $37^{\circ} .$. a gaseous content, measurable by the amount of oxygen, nitrogen, carbon dioxide, rare gases and water in the form of vapour'. ${ }^{4}$

Possibly the artist most influential on my own breath-inspired practice conceptually has been Cornelia Parker, whose Breathless (2001) can 
be viewed in the Victoria and Albert Museum. Parker's work creates many subtexts by literally taking the breath away from previously breathactivated objects. Perhaps its most poignant resonance is with what I think of as the 'breathlessness' of contemporary culture-the tendency apparent in many areas of life, encouraged by the impersonality of electronic rather than personal communication, to rush from one activity to another without pauses for meditation or considering any larger sense of shaping purpose. Parker asserts that all her work is about the in-breath and the out-breath. In Doubtful Sound, her 2010 exhibition at the Baltic Centre for Contemporary Art Gateshead, she presented a series of works which contrast the expansive, thrusting, independent dynamic which we relate to the expiration with that of the inspiration, a more reductive, distilled, compressed aesthetic which provides opportunities to consolidate, internalise and replenish. For Parker each instrument in Perpetual Canon (2004), an installation of sixty flattened brass band instruments in a circle, represents an in-breath, an 'inhalation never to be released' ${ }^{5}$ I see this affecting work as more relating to expiration, to having sighed in resignation and taken a final breath in the face of the sheer brute force of the 250-ton press which was needed to empty its internal cavity. I find myself imagining the force needed to re-inflate each of Parker's instruments, a process which appears impossible until we equate it with the initial inertia that the newly born lungs overcome for the first intake of breath. This effort is immense (three to four times that of a normal inspiration), and will not take place without the catalyst of external contact, whether the touch of the midwife or contact with the mother's abdomen. Whilst at the Baltic, I observed the magnetic quality of this work and its shadows. I particularly delight in the fact that viewers often connect with the work through their own breath: they literally blow into the shadow of an instrument's mouthpiece in an attempt to resuscitate the form.

Cornelia Parker's concerns about absence and presence of the breath are mirrored in Joseph Wright of Derby's An Experiment on a Bird in the Air Pump (1768). This work illustrates how controversial and shocking the scientific undertaking to understand the breath was in its day. The image, often misinterpreted as toying with the bird's existence, actually conveys attempts to understand the mechanics of resuscitation so as to save and improve lives. The work is rich in metaphor: for example, a Memento mori is suggested through the skull and candle, and the cockatoo, a rare and expensive bird, refers to the fragile and precious resource of the breath. Its setting, thought to be Erasmus Darwin's front room, 
is significant because it illustrates Wright's desire for collaboration to push forward the boundaries of science in a culture anchored in archaic thinking and practices. ${ }^{6}$

The final breath is a potent trope for our fragile hold on life. JacquesLouis David's portrayal of The Death of Marat (1793) evokes the poignancy of this inescapable liminal phase. The inevitability of transition has fuelled many pieces of visual art, and in my own practice I will always be moved by revisiting the image of a patient's breath that I recorded at the Hospice of St Francis just days before his death, an image which connects me directly back to the courage and humour this man demonstrated in the face of his situation. ${ }^{7}$

There are many examples of imagery serving to illustrate medical practice and procedures in the respiratory field. An engraving of Francisque Crotte applying his electrical remedy for tuberculosis to a seated woman (1901) served in its time to inform and inspire about advances in medical research, and today is valuable documentation of medical practice. However, for me personally, it sits uncomfortably as art: in art I want those qualities that make me feel the empathy articulated by Gabrielle Starr. Francis Bacon's Head VI (1949), on the other hand, based on a portrait of Pope Innocent $\mathrm{X}$ by the seventeenth-century Spanish painter Diego Velazquez, creates such a response. The image appears to convey the wretchedness of breathlessness. Jan Cox suggests 'that the subject is trying to draw in air ... gasping for breath, ${ }^{8}$ and therefore perhaps refers to Bacon's own experience of asthma. ${ }^{9}$ Bob Flanagan and Martin O'Brien, both performance artists, also channelled their abject individual experiences of living in the shadow of an incurable lung disease-cystic fibrosis-using endurance and in Flanagan's case sadomasochistic acts to communicate to audiences the protracted, excruciating reality of a life-limiting disease.

Not all breathlessness is pathological. In Several Interruptions (2009) Thomson \& Craighead create a series of five animated triptychs depicting individuals holding their breath under water, simultaneously attempting to escape the banality of normal life whilst grounding themselves by the crude physical sensation of asphyxiation. Thomson \& Craighead selected the fifteen video sketches from a resource of 61,000 possible clips posted on YouTube. Their presentation through the formal device of the triptych serves to illustrate the plurality of each individual endeavour. The holding of breath is perhaps among the most potent acts of conscious rebellion 
we can incite, and the resulting discomfort is manifested in the faces of those undertaking the endeavour.

Collaborative practice with the health service has given me the opportunity to explore what it is like to have lungs affected by breathing bad air, either voluntarily, through smoking, or involuntarily, through polluted air. From fracking to terrorism, pollution continues to concern us, and such concerns fuel work which reflects the implications of contemporary living. Artists such as Steven Jacobson depict the contemporary condensation trails we witness in our air space: we can admire the beauty of these chemical incisions, but are also aware of their impact on the environment. More menacing still are invisible threats: the once expansive feeling that air represented as a medium for exploration has shifted through warfare in the twentieth century towards air as a contracted zone of peril. In Terror from the Air (2009) Peter Sloterdijk argues that the first military use of chlorine gas in 1915 marked the beginning of a new age. The most sinister connection of air, breathing, and warfare cannot but be the use of gas chambers as instruments of civilian mass murder. Current proposals to place a Holocaust memorial in Victoria Tower Gardens, London, within sight of the British Houses of Parliament as a reminder of these atrocities, show how visual art can draw attention to the enduring nature of these threats while reminding us that we do have agency.

The breath has also been used to measure fear in a society necessarily concerned with security. In It takes 154,000 breaths to evacuate Boston (2007-2008) American artist kanarinka ran the entire evacuation route system in Boston and attempted to measure the distance in human breaths. The project challenges the ability of the city to respond to both terrorism and man-made disasters. Other artists have also striven to illustrate the threat to our breath of man-made issues. Kaya Hanasaki created Portrait in a Mask (2012) in response to the disaster at the Fukushima nuclear power plant. The work demonstrates a mistrust of government and was sponsored by Art Action UK, a collective of artists, curators, gallerists, and writers who are exploring various means to show solidarity and support for those affected by deliberate or negligent man-made disasters.

In this final section I have selected examples of visual art where breath has been used to represent literal or metaphorical spirituality. Breath holds significance in many religions. For both Judaism and Christianity the first book of the Torah and the Bible, Genesis, speaks of the 'breath of life' when God breathes life into the adamah (Hebrew: ground, earth). In 
a design in an illuminated manuscript originating in Canterbury (shown on the cover of this book), God is shown over the circle of the world with two long trumpets issuing from his mouth representing the breath of God, by which he 'breathed into [man's] nostrils the breath of life, and man became a living being' (Genesis, 2.7). ${ }^{10}$

The twelfth-century abbess, artist and activist Hildegard of Bingen described herself as 'a feather on the breath of God'. She is portrayed in the bottom left corner of the Cosmos, Body, and Soul mandala of the Liber Divinorum Operum, an image that shows the spherical earth being breathed into by ethereal creatures. ${ }^{11}$ I enjoy the lightness of touch that this imagery evokes, and I often feel I connect with such subtlety when collaborating with people in the recording of their breath, as, for example, in One Breath, a monoprint I made of a child's sigh. ${ }^{12} \mathrm{I}$ am fascinated by the sigh, because, while it has no verbal-semantic content in an ordinary sense, it is nevertheless polysemic and so communicative. I have used many different media to capture the sigh, and I have been influenced in this quest by Bernini's sculpture, The Ecstasy of St Teresa (1647-1652), which depicts the nun Teresa of Avila in religious rapture after spiritual contact with the angel with whom she is portrayed. Bernini's capture of this enigmatic breathing gesture in three dimensions, although criticised for its overt sensuality after his death, arguably was a direct response to the erotic terms in which the nun herself described the encounter.

Breath has been linked with spirituality in many ancient cultures, as in Ancient Egypt, where breath was associated with the concept of the soul. The funerary texts, The Books of Breathing (fourth century BCE to second century CE), for example, used breathing as a metaphor for all aspects of life that the deceased hoped to experience in the afterlife. Ancient Mesoamerican religions understood breath as a vital force. An image on the sarcophagus lid of the Mayan King Pakal (603-683) has been interpreted as Pakal descending into the underworld, or preparing for a cosmic journey, or falling into the open mouth of death where he breathes in a 'black hole' and moves into creation. Eastern traditions have long associated the breath with the spiritual. In Hinduism every movement is related to cosmic breath, and breathing practices such as pranayama, illustrated in the Bhagavad Gita (4.29), are a central spiritual practice with international and multicultural currency today. In some yoga practices life is measured not in years but in the number of breaths, each of which some yogis assert contains an unconscious prayer. Buddhists set great store by breath meditations to free the self from fleeting external and 
internal distractions, which explains why, after many breaths are poured into the creation of colourful sand mandalas, they can be promptly swept away with non-attachment.

Contemporary artists such as Shirazeh Houshiary aim spiritually to embody the breath. As she expresses it, 'I set out to capture my breath, to find the essence of my own existence, transcending name, nationality, cultures'. ${ }^{3}$ The same aim is common to Presence (2006-2007), in which she palimpsestically applies sacred Arabic text to the ground of a canvas, and to Breath (2013), which simultaneously video-projects evocative chants of Buddhist, Christian, Jewish, and Islamic prayers into a darkened space, creating an enigmatic breath-driven cacophony.

Mark Wallinger uses his breath to engage with religion through his alter ego, 'Blind Faith'. Hymn (1997) is part of a triptych, Talking in Tongues, in which breath is a central concern. It shows Wallinger standing on a soap box in a park, inhaling helium from a cylinder at his feet and holding a balloon as he sings a gloomy Victorian children's hymn in an uncanny high-pitched voice. This disconcerting vignette challenges us to consider faith, authority, and religion within contemporary society. The poignant references to childhood created visually and through the breath seem to suggest a yearning for spiritual, physical, and emotional renewal and yet acknowledge the implausibility of such an endeavour. Also a video installation, Martyrs (2014), by Bill Viola and Kira Perov, shows four individuals breathing stoically through assaults by the four classical elements. 'The elements represent the darkest hour of the martyr's passage through death into the light' (Bill Viola). ${ }^{14}$ A later commission, Mary, deals with the cycle from birth to death of the archetypal feminine. Mary, the mother of Christ, is here represented in a symbolic Anglican framework designed by Norman Foster. Creator Kira Perov speaks of Mary as the "embodiment of eternal sorrow... "container of the uncontainable", 15 and as iconically holding for us the transition of breath to breathlessness.

I hope this eclectic collection of imagery and concepts gives some idea of the ways in which artists have worked with breath to capture a range of its significances, literal and metaphorical. Gabrielle Starr considers how 'art changes human experience as it reorders our perceptions and engages our emotions'. ${ }^{16}$ Perhaps art about the breath creates an opportunity which can lead quietly back to the present-an anchor back to the experience of breathing in a breathless age. Starr argues that 'powerful aesthetic experience integrates information and sensation to redefine and 
revalue what we feel and know'. ${ }^{17}$ If, therefore, accessing visual imagery of the breath allows us to understand, empathise with and articulate our embodied experience, then, to borrow from Giorgio Agamben, perhaps we can engage with the humble breath as the quotidian which generates the pearl. ${ }^{18}$

\section{Part 2: My OWn Work-IN The Laboratory; in Hospital and Hospice}

As an artist working primarily to make breath visible, my practice has embraced study of the breath in the course of a Master's degree at the Slade School of Art, through collaborations, including with physicists at Brunel University and respiratory patients at the Royal Brompton and Harefield hospitals, and recently a commission to create twelve covers for The Lancet Respiratory Medicine journal. ${ }^{19}$ Over the last fifteen years, working with writers, musicians, physicists, engineers, students, and hospice and hospital patients and staff, I have produced drawings, installations, sculptures, and prints that reveal the shape and movement of the usually unseen breath.

Where does my desire to visualise breath come from? Perhaps the same sense of mystery that led Palaeolithic man to blow pigment across hands in the Cueva de las Manos. The breath is a source of fascination to me for a range of reasons. Perhaps its elusiveness and mercurial qualities most intrigue me. Breath lies literally at the centre of existence, allowing communication, movement, and thought. Perhaps it is the invisibility of this animating force which makes it so enigmatic, but I think it is also the ability of the breath to communicate experience, whether through voice or universal breathing gestures such as the sigh, that has made me long to pin down and record these moments which demonstrate the coexistence of resilience and fragility.

My interest in respiration in relation to visual art began in 2004 when I worked alongside patients in the Hospice of St Francis in Hertfordshire, $\mathrm{UK}$, many of whom suffered from breathlessness. Working in the hospice as an art practitioner, I ran monthly workshops with day- and in-patients, initially recording the patients' breath moving the flame of a candle in response to the Hospice's 'Light up a Life' campaign. I was moved by the generosity of patients in donating their precious, finite breath. I felt a responsibility to create something suitably celebratory from each patient's breath - an expressive record of a poignant moment. 
We often only pay attention to breathing-it only becomes visible to us-when it troubles us, when we are breathless in the face of some emotion, out of breath, or struggling for breath. Normally, when we can ignore it, breath is barely perceptible. When it takes a more material form, in the cold, or when the air is filled with pollutants, this is often a sign of danger, of decay, or of some limit being reached. It is probably relevant that my first exploration of all things respiratory goes back further than 2004, to my role in brand management for a pharmaceutical company where I worked on asthma management products. The commitment of respiratory physicians, GPs, asthma nurses, and respiratory health organisations to improving the lives of asthma patients inspired me, years later, to investigate breathing and breathlessness through my work. I have aimed to harness a wide and innovative range of materials to capture the breath, making the invisible visible. This led to a solo exhibition at Brunel University's Beldam Gallery in 2009, and then to a Leverhulme-funded residency, 'Inspired by Breath', in Brunel's Engineering and Design School.

The cross-disciplinary arts-science objectives of this residency reminded me of Joseph Wright of Derby's aim of using art to bring the cutting edge of science to the cultural fore. My work was less controversial-except possibly when presenting my film of cosmic ray demise, Darkness Visible, to a convention of particle physicists in Berlin, when I became aware of different notational priorities between the fields of arts and science. (I was delighted by the evocative indigos that resulted from inverting my film footage of the cosmic rays as they emerged within the cloud chamber. I was keen to retain the restrained monochrome palate which I felt allowed each unfolding form to speak for itself whilst also making art-historical references to traditional drawing inks used to render forms. My aesthetic decision was at odds with views of several physicists who felt colour coding each type of cosmic ray in post-production would have aligned more with scientific convention.) The primary aim of this residency was to allow me to continue my investigation into human breath as a fundamental unit of exchange between people and their environment. Our collaborative aim of developing innovative ways of making visible the normally invisible dynamics of the breath allowed me to reveal further forms that lie behind the verbal and non-verbal communication that the breath facilitates.

Professor Peter Hobson established an optical set-up in a laboratory at Brunel where we could explore the recording of breathing gestures and spoken words using the so-called 'Schlieren' system (named from the 
German Schlieren, streaks). This is a technique for recording subtle differences in refractive indices, such as would be provided by warm breath in cold air. A laser point source of light is expanded and then refocused by a mirror onto a knife-edge that blocks the direct light. Breathing in front of the mirror disturbs the light rays so that some bypass the edge and can be recorded by a camera behind it. Words were spoken in front of the mirror while I photographically recorded the patterns produced by the turbulent air, as in Plate 23.1.

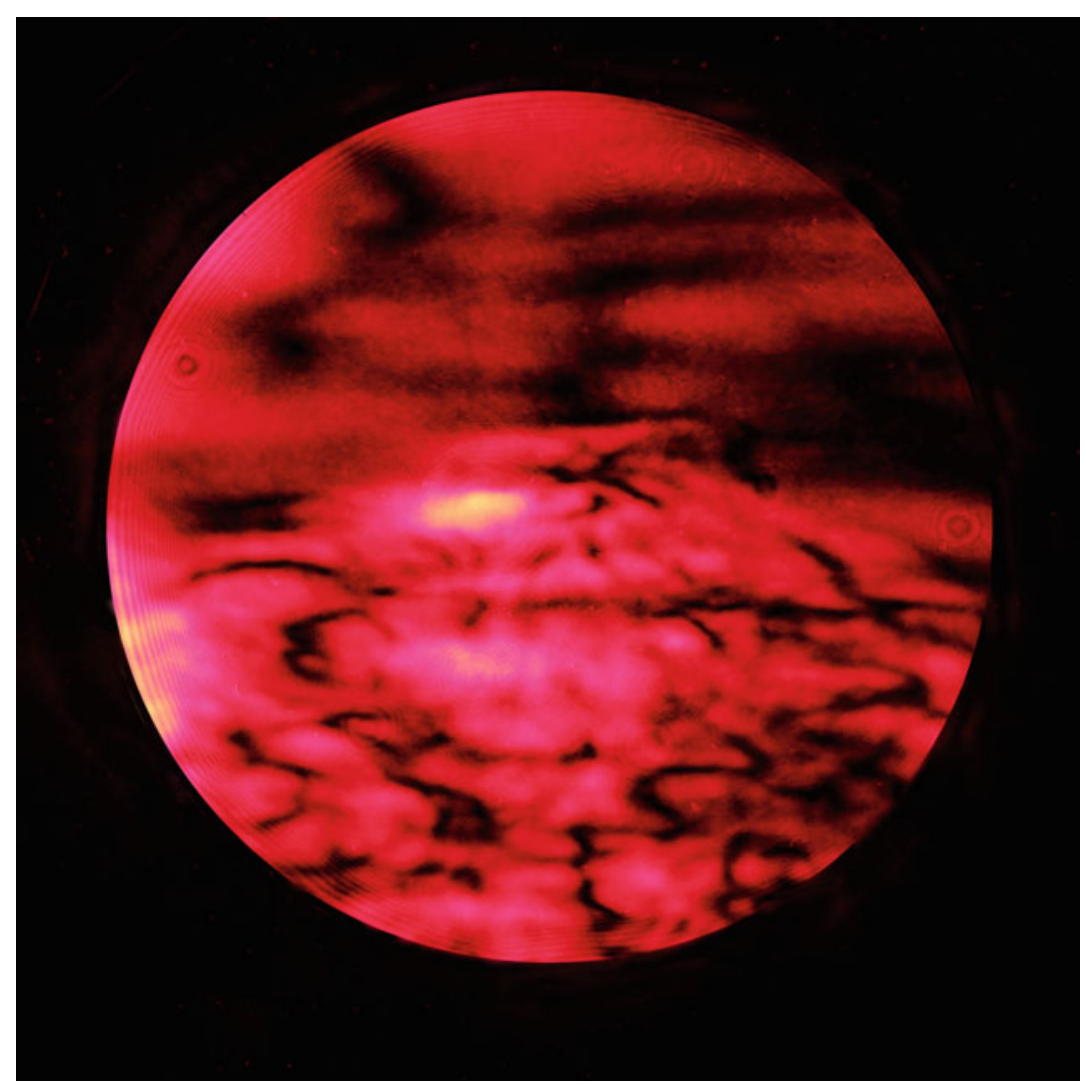

Plate 23.1 Schlieren capture of the word 'I'. (C) Jayne Wilton 
Multiple recording sessions allowed us to build up a library of words and breathing gestures such as the gasp, the sigh, and breath-carried sounds of spiritual significance such as 'Om', captured as Schlieren images. We installed three of these in the Brunel Library Special Collections room where they can be seen from both inside and outside the building. An objective for the residency was to be able to make words visible, and hence, the breath that carries the voice. In order to work with words that were not merely randomly selected I drew on the research of Anna Wierzbicka on universal semantic primes, in other words, key words across cultures that are posited as critical to facilitating face-toface communication. ${ }^{20}$ Also using this set of sixty words, I worked on inter-semiotic translation of sound into imagery or form using fluid dynamic technology to model a series of these words. I sought volunteers at Brunel University, representing different groups of the University's community from students to academics, to speak one or more words from the list. By gathering a diverse sample of vocalised words from across the Brunel community, I hoped to allow a sampling of timbre, dialect, intonation, and articulation of the key semantic primes. This sound recording was then used to generate a three-dimensional sculpture using the 'Maya' programme, a software package which facilitates $3 \mathrm{D}$ animation, modelling, simulation, and rendering, and which is often used to simulate fluid dynamics. The forms were 3D-printed in the School of Engineering and Design, allowing the audience literally to 'hold' pieces of conversation. This translation of voice into form created an evocative resource through which to raise questions about how carefully or recklessly we use these tools in our daily lives. The words created in this project included 'because', 'think', 'moment', and 'happen'. One word from outside the list of semantic primes was chosen by Brunel University's chair of Creative Writing, Benjamin Zephaniah, who, reflecting on the empathetic objective of the project, wanted to record 'overstanding' (Plate 23.2), an invented word, a word that he thinks he heard in Jamaica or in a dream, which he prefers to 'understanding', which he sees as carrying potentially patronising connotations. In his view, "“overstanding" transcends "understanding" by incorporating the qualities of empathy, humility, and compassion. It implies a sense of overview, and a wider or broader comprehension of a phenomenon'. ${ }^{21}$

Continuing in my quest to make visible the dynamics of the human breath, I collaborated with particle physicists Peter Hobson and Ivan Reid, who both have specialist experience of in-line digital holography 


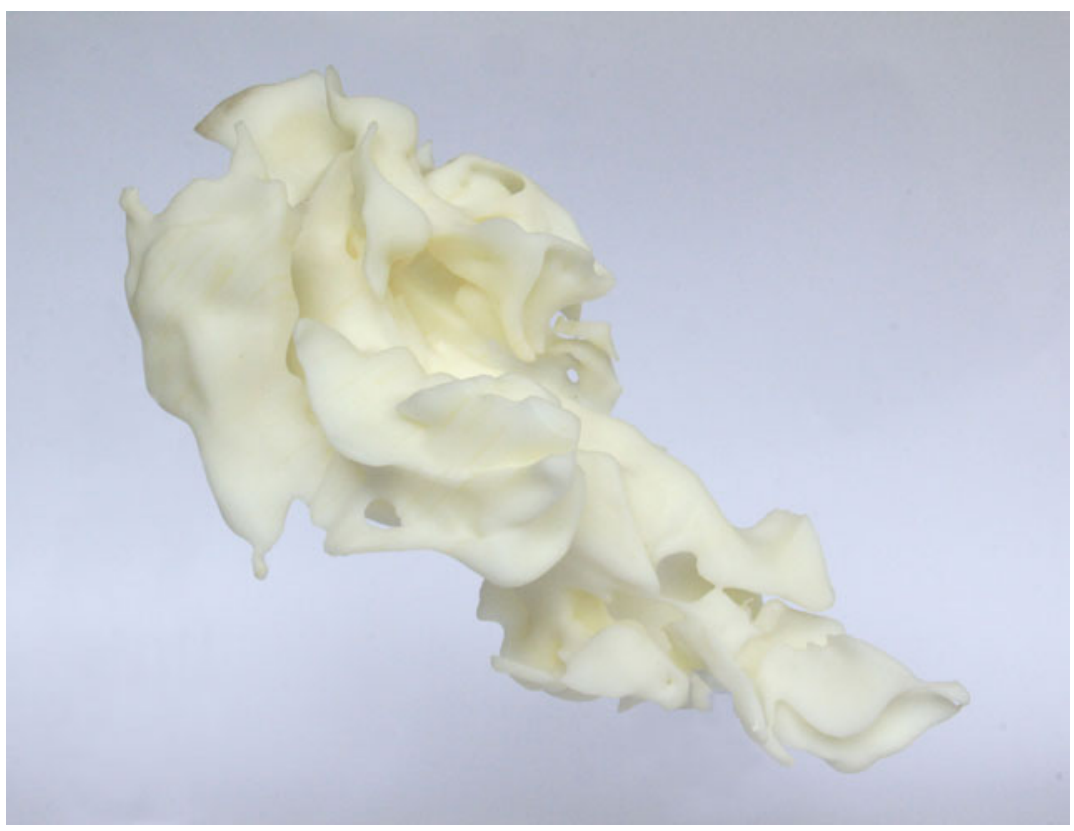

Plate 23.2 Conversation piece, Overstanding. (C) Jayne Wilton

and its computer reconstruction. The creation of digital holograms of breathing patterns provides the three-dimensional illustration of the dynamics at work when a breath is expired. In-line digital holograms were recorded using a fast-pulsed green laser and a $36 \times 24 \mathrm{~mm}^{2} \mathrm{CCD}$ camera in an optics laboratory established by Professor Hobson.

Digitalis seeds, selected for their aerodynamic properties, were expired into an acrylic chamber and their trajectory recorded. The holograms were replayed using HoloMovie software that runs on a multi-core NVIDIA GPU. Real time digital hologram replay allows the audience to move through holograms of breath-borne particles. Reid enhanced the footage using 'edge detection', which allows the seeds to be seen coming in and out of focus as the camera moves through the holographic replay. ${ }^{22}$ The rhythm of the breath provides a fundamental measure of our functioning, so to visualise the complexity of such a universal dynamic could stimulate new insights for technological modelling in wider fields of scientific research. 
Most of us will have experienced playing with the interaction of our breath with shiny surfaces such as windows and mirrors, creating temporary fields of condensation in which to doodle. In emergency situations a mirror or shiny surface is held in front of the mouth of a subject to confirm whether or not he or she is breathing. My Breathe series, a sequence of evocative landscapes which both employ and subvert traditional printing processes, makes use of these dynamics. In November 2012 I travelled with Peter Hobson to CERN, the European Organization for Nuclear Research, to record the breath of colleagues working on the CMS and ATLAS particle detector experiments. Breathe is a celebration of their role in the first observations of what may well be the long-sought Higgs boson at the Large Hadron Collider. Their breath was captured on the copper surface and etched to create a negative of the breath where it initially sat. I simultaneously recorded the breath of Brunel physicists also working on these projects, and exhibited the plates together intermingled to demonstrate the interconnectedness of the two sites and the importance of collaborative projects.

My fascination with recording human breath led me to consider notions of recording the 'breath' of the universe. Peter Hobson introduced me to the idea of cosmic rays as an indicator of universal expiration. We filmed cosmic rays using an acrylic diffusion cloud chamber in Hobson's laboratory at Brunel. The recording of cosmic rays in this way is well documented and can be viewed on social networking and sharing sites such as YouTube. The challenge was to look anew at these traces and open up new perspectives on these ephemeral forms. I wanted to create a more immersive environment where the audience could consider the decay of these supernova remnants as positive forms rather than negative trails. Inverting the film footage created such an opportunity. The negative trails become positive entities, which can be viewed undertaking their entropic demise. The viewer then experiences the dark absence of the decaying rays as ebullient present forms.

HD filming of the events under tungsten lighting allowed the yellow hues that lit the traces to become violet and deep indigo when inverted, evoking the interstellar space from which the rays have travelled. The resultant film, Darkness Visible, became an exploration of the use of light to make visible these normally invisible forms and generate imagery not normally associated with the monochromatic traditional capture of cosmic events. $^{23}$ (Plate 23.3) 


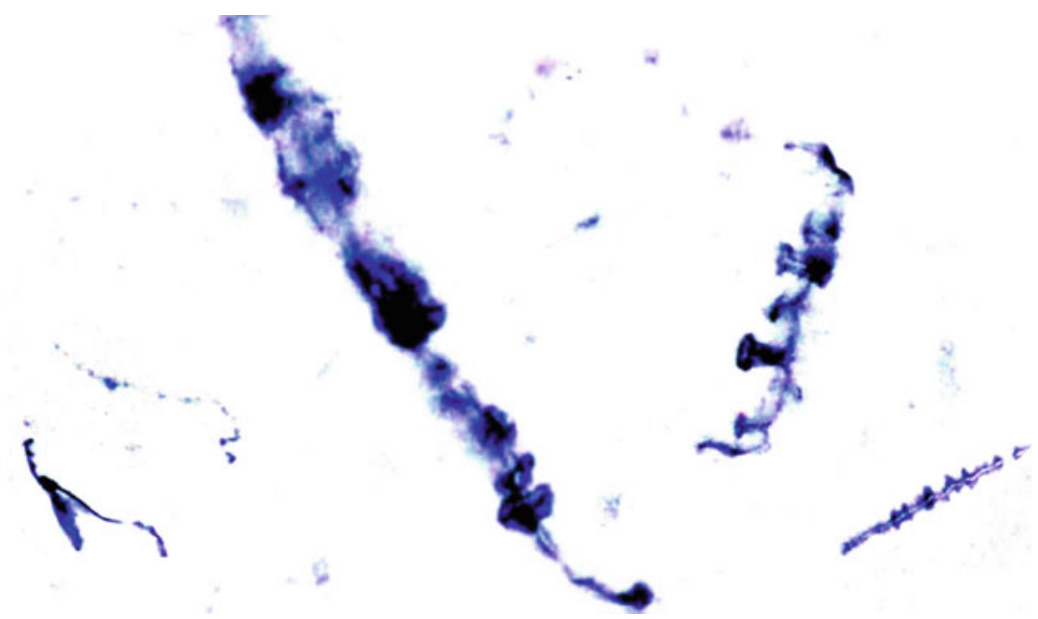

Plate 23.3 Still from Darkness Visible showing cosmic ray demise. (C) Jayne Wilton

$$
* * *
$$

In 2014 an Arts Council England grant enabled me to undertake a period of research and development, leading to a series of participatory workshops with patients at the Royal Brompton and Harefield hospitals. The project was an opportunity to collaborate with a hospital specialising in heart and lung disease, and resulted in a body of work including a series of copper plates onto which the breath of patients in the pulmonary rehabilitation unit was recorded. Working alongside a composer, curator, clinical research physiotherapist, and three respiratory groups, I created drawings and installations that captured the usually unseen human breath in a variety of media. ${ }^{24}$ The outcomes of this project resulted from participation with the three patient groups: a 'Singing for Breathing' group, a 'Breathe Easy' group, and patients in the pulmonary rehabilitation unit.

'Singing for Breathing' was a singing workshop in which up to twentyfive patients met twice each week. I was intrigued by the abstract nature of breathing gestures used for the group warm-up, and the workshop leader, Joanna Foster, agreed to compose a vocal piece based on these gestures for the group to perform as a round. The outcome was an animation, Vent, which visualises the dynamics of interaction between the 
three sung parts of a round, and in which listening to the rich texture of the combined voices within each group is as important as watching the physical dynamics unfold. ${ }^{25}$ I was struck to realise when creating this animation that the rhythm and dynamics of the piece were acting as a metronome for my own breath, an index of how deeply collaborations engage us at a personal as well as a professional level.

The 'Breathe Easy' group is a support group for patients with lung disease, supported by the British Lung Foundation (BLF). With this group I ran a series of sessions recording on photographic film the breath of individuals, which resulted in a number of installations including Crowd (Plate 23.4) and Cacophony (Plate 23.5).

With patients in the Pulmonary Rehabilitation Unit I created Breathe, a series of ten etched copper plates (Plate 23.6). The Breathe series makes use of the dynamics of breath interacting with a cold shiny surface. Capturing the condensation of a spent breath on the surface of a copper plate and then etching it into the surface creates a unique series of marks and colours, abstract in nature. Preserving an individual and nuanced trace of the individual's breath at a specific moment presents an alternative to traditional portraiture. This work employs traditional lithographic processes but also subverts and challenges the notion of etching as a specialist process by allowing compositions and drawings to be made by the humble breath. The inscription of expiration onto precious metal immortalises a discharge and makes visible an otherwise unseen exhalation.

In the case of the Breathe project, visual outcomes of breathing or singing onto photographic film rested on an alchemy which I associate with Marcel Duchamp's concept of 'infra-mince' (French: an invented term based on mince, thin: hence 'less than very little'). Though Duchamp claimed the idea could only be exemplified, not defined, one might say that this involves liminal situations that result in real and significant, albeit barely discernible, changes. ${ }^{26}$ These occurred in the intense darkroom situation where the performance took place. There was a buzz of excitement in both workshops as patients prepared for their sessions and then discussed their experience of the darkroom 'tent' with their peers. The transaction that took place between artist, materials, and performer generated ephemeral records with the potential to open up subtle pathways and alter perceptions. Such shifts of perception can serve to invigorate the acuity of the gaze, or result in a call to compliance with clinical advice, even if only through the novelty of the encounter. 


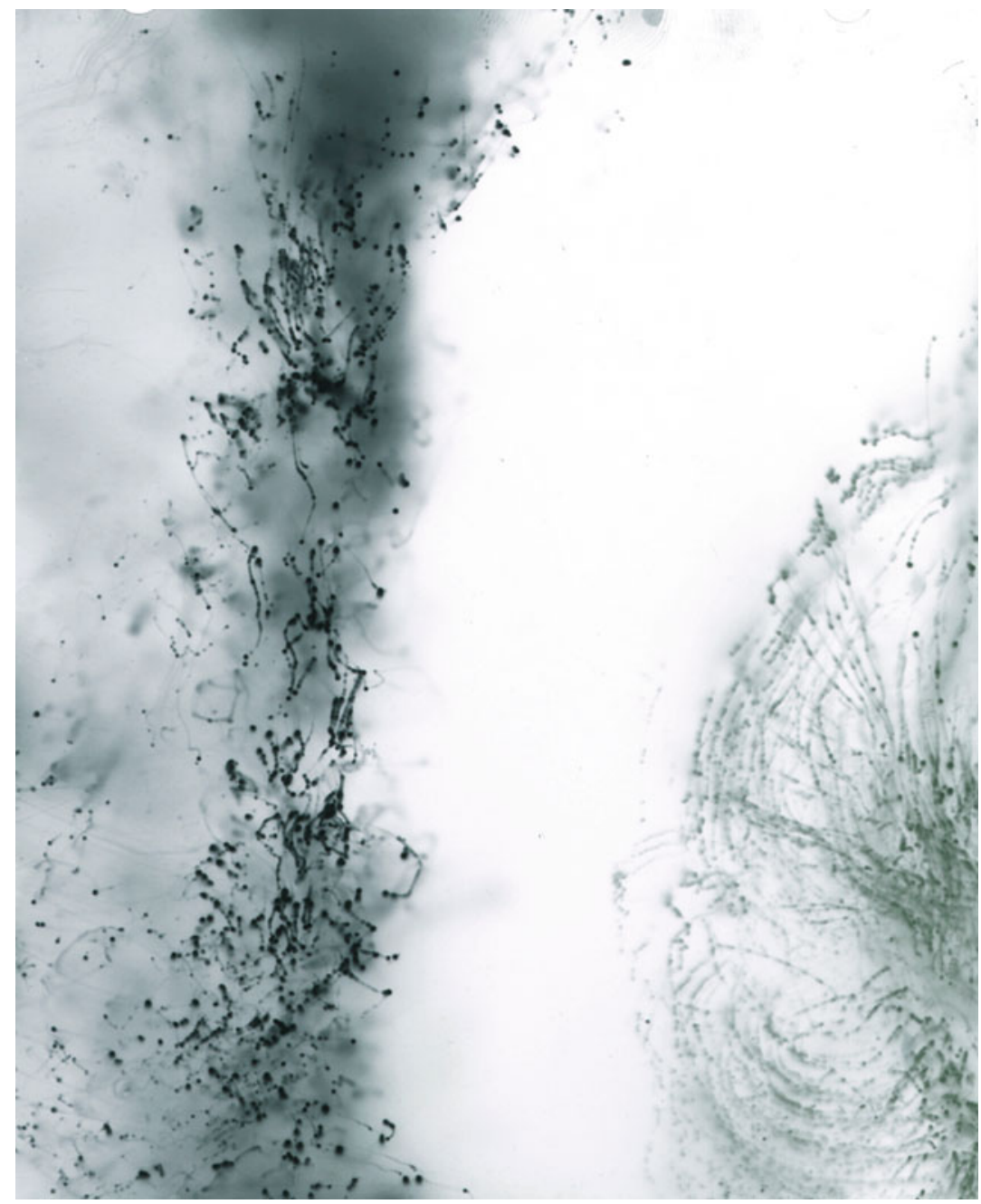

Plate 23.4 Crowd, layered drawings from the Sing series installed in Perspex blocks. (C) Jayne Wilton 


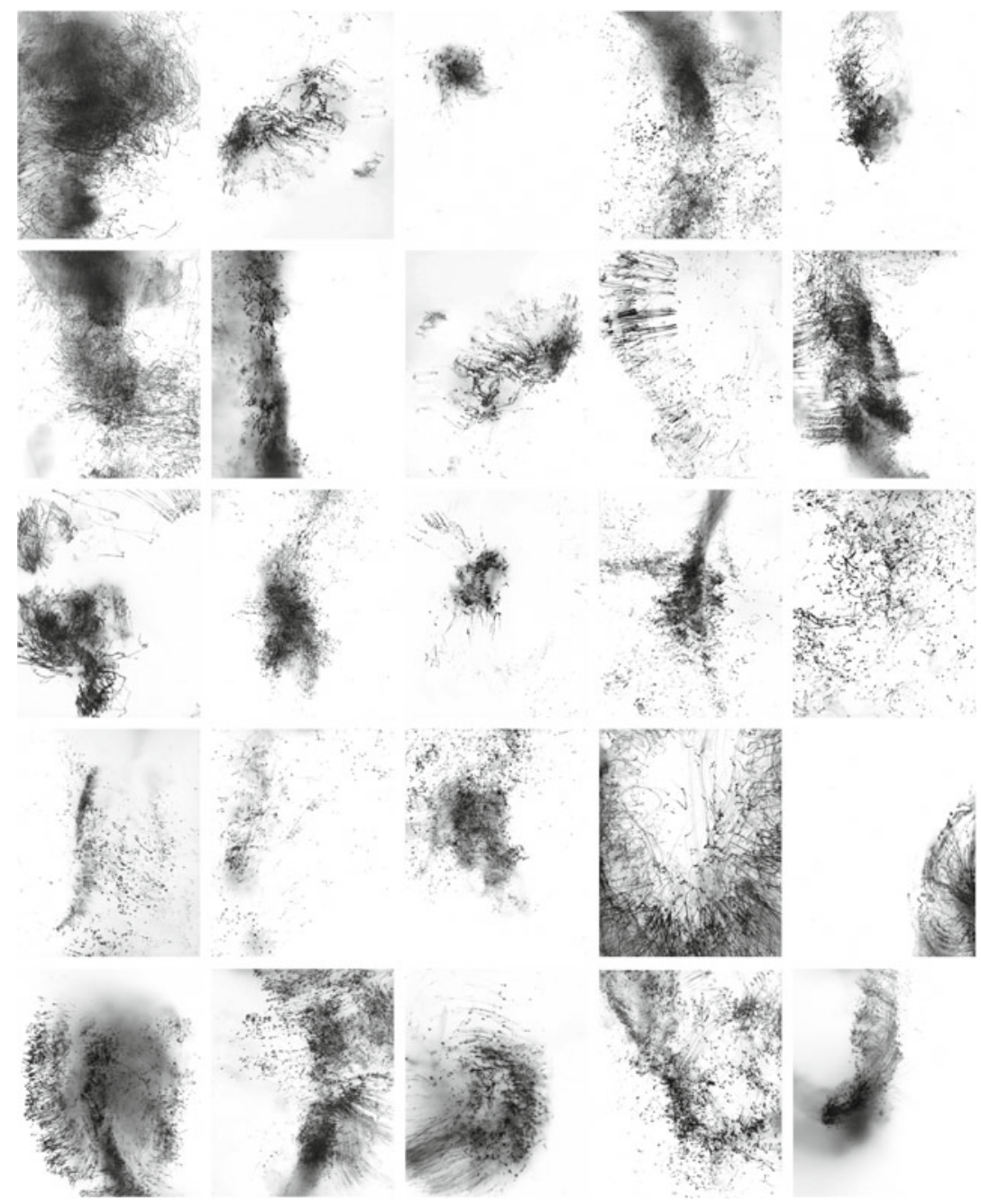

Plate 23.5 Cacophony, composed of twenty-five examples of the series Sing. (C) Jayne Wilton 


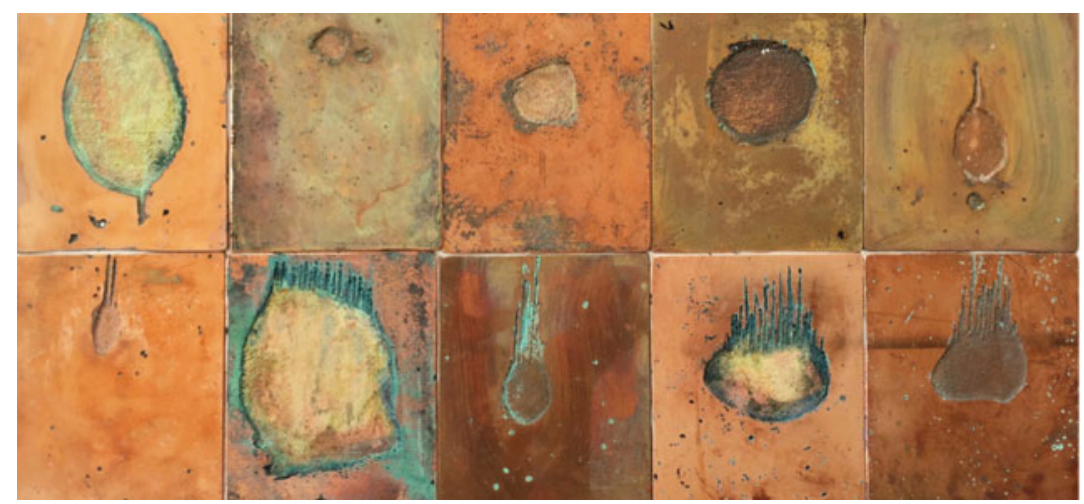

Plate 23.6 Breathe, plates created with patients and staff in the Royal Brompton Hospital. (C) Jayne Wilton

Walter Benjamin identified a modern alienation from experience initiated by the difficulties of assimilating atrocities encountered on the battlefield in World War I where 'a generation ... now stood under the open sky in a countryside in which nothing remained unchanged but the clouds, and beneath the clouds, in a field of force of destructive torrents and explosions, was the tiny, fragile human body'. ${ }^{27}$ This 'poverty of experience' is explored further by Giorgio Agamben, who attributes it to our distancing ourselves from even day-to-day seemingly banal events, where we hold at arms' length experiences as a buffering mechanism to shield us from their intensity. ${ }^{28}$ In this way it is possible to consider processes and media which visualise experience as serving to protect the participant from the direct gaze on his or her condition while simultaneously providing proprioceptive access to the experience. Whatever the mechanism may have been, taking part in these activities seemed to exceed patients' expectations of how much they would enjoy or benefit from them. Many reported a greater awareness of the value of the arts in terms of pleasure, wellbeing, and health.

I often wonder why collaborative projects which connect us to an expanded sensory experience of breath can command such commitment from participants. Perhaps such shared creative encounters catalyse a subtle assimilation of experience, a reconnection with the authority of felt experience. Participants from the Royal Brompton Hospital were still committed enough six months after the project had ended to travel across 
London to re-perform and celebrate it. Nicolas Bourriaud's concept of relational aesthetics in contemporary art practice seems to offer a further clue: it is necessitated, he argues, by the fact that 'this is a society where human relations are no longer "directly experienced". ${ }^{29}$ Perhaps the need for engagement in contemporary society is ignited by new ideas or projects making new neural pathways, reopening possibilities of sensed experience, a seeping back of connection. It may be that true conviviality, sociability, and humane exchange are in the forefront of art today because they are scarce elsewhere.

Patients are used to visualisation of the clinical indicators of their lung capacity and breathing quality through graphs and charts. However, when patients were invited to create non-clinical records of their breath as part of an art practice, there was a level of excitement and anticipation, and in some cases nervousness and reticence, when contemplating taking part. Visualisation can reinvigorate the interaction between clinician and patient, perhaps even help us to understand the emotional landscape which comes with the long-term suffering of patients with COPD, asthma, and other causes of breathlessness. Art can shift the focus to joint ownership of the problem, the novelty of the resulting image thus allowing neutral ground to mediate the gap between the physician's scientific knowledge about lung function and the sufferer's experience of it. The explicatory value of using art to reify the transitory breath may facilitate a less intimidating dialogue around clinical markers of symptomatology. An arrested moment can pierce the haze of inertia, allowing a clarity, a bridge between our experience of our breath and the knowledge of our condition.

What I also get out of collaborative work is the unexpected alchemy that unfolds. When working with the breathing of impaired lungs, while you are necessarily illustrating the limitations of the system, it does nevertheless also seem possible to see resilience alongside the fragility.

\section{Notes}

1. Gabrielle G. Starr, Feeling Beauty: The Neuroscience of Aesthetic Experience (Cambridge: MIT Press, 2015), 80 and 99.

2. Most of the works discussed in this chapter can be viewed by putting the name of the artist and the title of the work into an internet search engine. Here, for example, see https://en.wikipedia.org/wiki/Cueva_de_ las_Manos. 
3. Christiana Payne, 'The First Balloon Flights: Art and Science', in Air: Visualising the Invisible in British Art 1768-2017, ed. by Gemma Brace (Bristol: Sansom, 2017), 12.

4. http://www.philipperahm.com/data/projects/pulmonaryspace/index. html.

5. Cornelia Parker, quotation from Doubtful Sound exhibition guide, Baltic Centre for Contemporary Art, 2010.

6. I am indebted to the research of Alan Barnes (Derby University) and Stephen Leach (Keele University), delivered in the 2017 symposium, 'Breath, Flight and Atmosphere', for fresh insights into this seminal work.

7. Courageous Breath can be seen at https://www.jaynewilton.com/ drawing-breath.

8. Jan Cox, 'Wyndham Lewis and Francis Bacon', https://www.unirioja.es/ listenerartcriticism/essays/essay-Wyndham-Lewis-and-Francis-Bacon.htm.

9. Michael Peppiatt, Francis Bacon: Anatomy of an Enigma (London: Weidenfeld, 1996), 24.

10. British Library, Royal 1 E VII, f.lv (this leaf, third quarter of the eleventh century) https://www.bl.uk/catalogues/illuminatedmanu scripts /ILLUMIN.ASP?Size $=$ mid\&IllID $=40497$.

11. Liber Divinorum Operum 1.4: Cosmos, Body, and Soul. Biblioteca Statale di Lucca, MS 1942, fol. 38r (early 13th century) http://www.hildegardsociety.org/p/liber-divinorum-operum.html.

12. One Breath can be seen at https://www.jaynewilton.com. It was recorded at Brunel University in 2011 during a STEM outreach project.

13. https://www.lissongallery.com/artists/shirazeh-houshiary.

14. http://billviolaatstpauls.com/martyrs/.

15. http://billviolaatstpauls.com/mary/.

16. Gabrielle Starr, Feeling Beauty, 28.

17. Ibid., 2.

18. Giorgio Agamben, Infancy and History: On the Destruction of Experience, trans. by Liz Heron (London: Verso, 1993), 16.

19. All covers and cover stories created for this commission can be found at https://www.jaynewilton.com/2016-respiratory-lancet-coversand-stories.

20. See Anna Wierzbicka, Cross-Cultural Pragmatics: The Semantics of Human Interaction, Trends in Linguistics: Studies and Monographs 53, 2nd edn (Berlin: de Gruyter, 2003), 8. Wierzbicka identified sixty semantic primes which form the basis of a natural semantic meta-language and are core words critical to communication in all major languages.

21. Jayne Wilton, George Mogg, and Malcolm Zammit, Suspense (London: Brunel University, 2013), 19. See https://itunes.apple.com/gb/book/ suspense/id661082571? $\mathrm{mt}=11$. 
22. The Edge of Suspense can be seen at https://www.youtube.com/watch?v= DSVeJnlYP6k\&feature $=$ youtu.be.

23. https://www.youtube.com/watch? $v=X S v w 2 G a M J o Y \& t=68 s$.

24. This project was delivered in partnership with the Royal Brompton and Harefield NHS Foundation Trust's charitably funded arts programme.

25. The Vent animation can be seen under the Drawing Breath section at http://www.jaynewilton.com.

26. For Duchamp's attempts to exemplify the idea see Marcel Duchamp, Notes, preface by Pontus Hulten, intro. and trans. by Paul Matisse (Paris: Centre George Pompidou, 1980).

27. Walter Benjamin, 'The Storyteller', in Illuminations, trans. by Harry Zohn (Pimlico: London, 1999), 83-84.

28. Agamben, Infancy and History, 15-17.

29. Nicolas Bourriaud, Relational Aesthetics, trans. by Simon Pleasance and Fronza Woods (Dijon: Presse du réel, 2002), 9.

\section{Selected Bibliography}

Agamben, Giorgio. 1993. Infancy and History: On the Destruction of Experience. Trans. Liz Heron. London: Verso.

Brace, Gemma (ed.). 2017. Air: Visualising the Invisible in British Art 17682017. Bristol: Sansom.

Benjamin, Walter. 1999. Illuminations. Trans. by Harry Zohn. Pimlico: London. Bourriaud, Nicolas. 2002. Relational Aesthetics. Trans. by Simon Pleasance and Fronza Woods. Dijon: Presse du réel.

Sloterjijk, Peter. 2009. Terror from the Air. Trans. by Amy Patton and Steve Corcoran. Los Angeles: Semiotext(e).

Starr, Gabrielle G. 2015. Feeling Beauty: the Neuroscience of Aesthetic Experience. Cambridge: MIT Press.

Wierzbicka, Anna. 2003. Cross-Cultural Pragmatics: The Semantics of Human Interaction. Trends in Linguistics: Studies and Monographs 53, 2nd edn. Berlin: De Gruyter. 
Open Access This chapter is licensed under the terms of the Creative Commons Attribution 4.0 International License (http://creativecommons.org/licenses/ by $/ 4.0 /$ ), which permits use, sharing, adaptation, distribution and reproduction in any medium or format, as long as you give appropriate credit to the original author(s) and the source, provide a link to the Creative Commons license and indicate if changes were made.

The images or other third party material in this chapter are included in the chapter's Creative Commons license, unless indicated otherwise in a credit line to the material. If material is not included in the chapter's Creative Commons license and your intended use is not permitted by statutory regulation or exceeds the permitted use, you will need to obtain permission directly from the copyright holder.

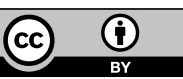

